\title{
A Natureza Jurídica dos Consórcios Intermunicipais e as Conseqüências Trazidas pela Lei no. 11.107/05 ${ }^{1}$
}

The Legal Nature of Consortia and the consequences brought by Law No. 11.107/05

Jairo Henrique Scalabrini ${ }^{2}$

\section{Resumo}

\begin{abstract}
A gestão associada de serviços públicos, pela formação de consórcios de entes federados (municípios, estados e União), é uma forma de realização das atividades estatais primordiais, como a saúde, cuja demanda é sempre crescente e não é vencida pelo sistema de distribuição da arrecadação, até então vigente. 0 pacto federativo é melhor engendrado na forma cooperativa, pois permite a aplicação personalizada de recursos e serviços, atendendo cada região de acordo com suas reais necessidades. E a lei $n \circ$. 11.107/05 veio justamente regulamentar uma prática que estava instalada há tempos, com o intuito de dar mais transparência e controle as ações dos gestores destes consórcios públicos, apesar de trazer também consigo algumas incertezas jurídicas decorrentes de pouca técnica legislativa.
\end{abstract}

Palavras-chave: consórcio intermunicipal, autonomia, federalismo cooperativo, gestão associada.

\begin{abstract}
The associated management of public services by forming consortia of federal entities (cities, states and Union) is an execution of primordial state activities, such as healthcare, where demand is growing and is not always won by the distribution system collection, then in force. The federal agreement is better engineered in a cooperative way, because it allows the custom application of features and services, meeting each region according to their real needs. And Law No. 11.107/05 came precisely regulate a practice that was installed some time ago, in order to give more transparency and control the actions of managers of these consortia, while also bringing with it some legal uncertainties arising from poor legislative drafting.
\end{abstract}

Keywords: inter-municipal consortium, autonomy, cooperative federalism, associated management.

\footnotetext{
1 Artigo apresentado à Universidade Estadual de Londrina, como requisito parcial à obtenção do título de Especialista em Direito do Estado, sob a orientação do Prof ${ }^{\circ}$. Luz Henrique U. Cademartori.

2 Bacharel em Direito graduado pela FADAP-Faculdade de Direito da Alta Paulista, em 1997.
} 


\section{Introdução}

É prática comum dos pequenos municípios de uma micro-região, constituir consórcios intermunicipais para engendrar a gestão de projetos de interesse regional, em especial a de saúde pública, em função da falta de estrutura individual para fazer frente a estas demandas sempre crescentes, bem como da pequena participação da arrecadação fiscal nacional.

Os entes fictícios federal e estadual cada vez mais descentralizam a gestão de políticas públicas aos municípios, como é o caso da educação no Estado de São Paulo e o Sistema Único de Saúde, porém, mantém para si a maior parte do produto da arrecadação fiscal que seria destinada a financiar o atendimento dessas áreas.

Assim é que os pequenos municípios começaram a se associar em forma de consórcios criados através de uma pessoa jurídica de direito privado, que recebem verbas públicas creditadas aos municípios, por vezes do Sistema Único de Saúde e, com isso, contratam hospitais, obras, cursos profissionalizantes e diversos serviços que, pelo valor, não seriam possíveis a um único município.

Originária de estímulos vindos da União ou dos Estados, ou emanada de uma política local, essa cooperação pressupõe a existência de políticas "autônomas" nos diversos níveis de governo. É esta autonomia que permite que a efetiva colaboração ocorra sem subordinação dos municípios aos programas federais ou aos municípios de grande porte.

Mas a forma como esses consórcios são criados está sujeitando esses municípios e seus prefeitos a uma série de demandas judiciais, em todas as esferas, pois acabam incorrendo em desvio de finalidade, improbidade administrativa, repasse de verbas ou em duplicidade, dentre outras ilegalidades.

A doutrina sempre divergiu acerca da natureza jurídica destes consórcios, ora dizendo que são pessoas jurídicas de direito público, independente da forma de constituição, ora atestando sua natureza privada e, por fim, até mesmo sustentando não haver personalidade jurídica, mas apenas um contrato firmado entre vários municípios.

A Lei Federal №. 11.107/2005, encerrou uma longa espera nos três níveis da Federação, que agiam na ausência de regulamentação da gestão associada de entes federativos, já positivada entre nós pela Emenda Constitucional no 19/98. Ela trouxe 
institutos jurídicos modernos e consagrados, como as parcerias público-privadas e os consórcios públicos.

Porém, acabou por tornar mais confuso esse modelo de comunhão de esforços, pois em vários de seus dispositivos trata do consórcio como pessoa jurídica de direito público e em outros o admite como pessoa jurídica de direito privado.

A regulamentação do instituto do consórcio público veio reforçar a tendência de não mais encarar o direito administrativo "como mero conjunto de normas voltadas a regular o exercício da função administrativa" (FREITAS, 2004, p. 87), mas como verdadeira ciência que contempla os princípios e valores fundamentais da Administração Pública a nível constitucional.

Assim é que a exegese da lei dos consórcios e a pacificação da doutrina e da jurisprudência, acerca das suas várias nuances, é fundamental para o sucesso e o controle de tais empreendimentos.

A proposta deste artigo é justamente discutir a natureza jurídica destas associações, suas formas de constituição e conseqüências e, principalmente, qual seria o modelo ideal para atender o necessário interesse público.

\section{Histórico das associações de municípios na administração publica brasileira}

As associações de municípios já eram previstas na Constituição de 1937, mas sem regulamentação própria, nem estimulo para sua formação, pela ausência de um programa de descentralização política que reconhecesse o município como ente federado coadjuvante do desenvolvimento nacional.

Antes da regulamentação, os consórcios intermunicipais se formavam com base em legislação civil, utilizando-se, portanto, de regras de direito privado. Pessoas jurídicas de direito público, notadamente os entes federados, se tornavam sócias de uma pessoa jurídica de direito privado, tendo como presidente um dos prefeitos, eleitos pelos demais e dessa forma promoviam ações na área da saúde, turismo, transporte, por vezes adquirindo máquinas e implementos para uso comum na microrregião, mediante pagamento de uma cota mensal ou o repasse de verbas oriundas de outros entes da Federação, através de convênios e subvenções. 
Centenas de consórcios funcionam no País, principalmente na área da saúde, que congrega mais de 2.000 municípios. Essa prática crescente chamou a atenção do Tribunal de Contas, que constatou a necessidade de regulamentar a "composição e forma de apresentação das prestações de contas de exercício dos responsáveis pelas associações microrregionais de municípios e pelos consórcios intermunicipais de saúde.", já que a legislação vigente, ou a falta de uma regulamentação própria do setor, deixava muita margem de liberdade para a atuação dos chefes do Poder Executivo, favorecendo a fraude e o desvio de verbas, inviabilizando também uma atuação mais próxima das Cortes de Fiscalização.

Segundo Di Pietro (2009), havia na doutrina o consenso de que os consórcios administrativos não adquiriam personalidade jurídica e eram comparados aos consórcios privados previstos da Lei das Sociedades Anônimas ( Art. 278 e $\S 10$.). Eram tidos como agrupamentos de pessoas que se responsabilizavam em nome próprio, segundo os direitos e as obrigações previstas no respectivo termo, como funcionava nos convênios, que tinham por objetivo reunir pessoas "interessadas na execução de obras ou serviços de interesses mútuos", mas sem a constituição de uma personalidade jurídica distinta dos conveniados, como explica Carvalho Filho (2007, p. 199):

\footnotetext{
"Os consórcios, tradicionalmente, nada mais eram do que convênios, instrumento em que pessoas públicas ou privadas ajustam direitos e obrigações com o objetivo de alcançar metas de interesse recíproco. Em outras palavras, sempre foram negócios jurídicos pelos quais se pode expressar a vontade de cooperação mútua dos pactuantes."
}

A Constituição Federal de 1988 agregou complexidade à estrutura federativa brasileira, reconhecendo o município como ente federado, apesar de haver ainda divergência doutrinária sobre o assunto. Tal atitude visava trazer maior descentralização das políticas públicas, através do fortalecimento do poder local, sem porém engendrar políticas de desenvolvimento regional, o que acentuou as desigualdades locais e regionais observadas historicamente no país.

A partir da Emenda Constitucional no 19/98, instituidora da Reforma do Aparelho Administrativo do Estado, verificou-se na concretude, a flexibilização do Direito Administrativo Brasileiro, acompanhando as tendências mundiais, como na Alemanha e na 
França, do final do século XX. Nesse sentido, Di Pietro (2005, p. 55) lembra que aqui houve a "instauração da chamada Administração Pública Gerencial, que envolve: maior discricionariedade para as autoridades administrativas, substituição do controle formal pelo controle de resultados, autonomia administrativa, financeira e orçamentária..." (PIETRO, 2005, p. 55).

Essas transformações, ocorridas nas últimas décadas em nosso país, iniciaram uma crescente interpenetração entre os direitos público e privado, afastando a dicotomia até então em vigor. Assim, o Direito Administrativo veio de encontro à tendência de se criar entidades de direito privado por entes federativos, especialmente municípios, como forma de facilitar a atuação conjunta em matérias de interesse regional ou para representar os interesses de seus integrantes.

E, dessa forma, começou o ordenamento jurídico a conceituar e interpretar de forma científica, a atuação dessas entidades. Porém, essa flexibilização do Direito administrativo, por vezes acabou por atrapalhar a sistematização necessária a uma boa exegese.

O consórcio público e seus institutos afim foram positivados na nova redação do art. 241, modificado pela Emenda Constitucional no 19/98, que determinou a regulamentação, por lei, da gestão associada dos entes federados:

\footnotetext{
“Art. 241. A União, os Estados, o Distrito Federal e os Municípios disciplinarão por meio de lei os consórcios públicos e os convênios de cooperação entre os entes federados, autorizando a gestão associada de serviços públicos, bem como a transferência total ou parcial de encargos, serviços, pessoal e bens essenciais à continuidade dos serviços transferidos."
}

Com o objetivo de regulamentar o dispositivo constitucional acima e dar segurança jurídica e administrativa aos consórcios intermunicipais até então já instalados, bem como por estimular a criação regular de mais associações como esta e desonerar os entes federativos fictícios, iniciou-se a discussão do projeto da lei de consórcios em agosto de 2003 pela Secretaria de Coordenação Política e Assuntos Institucionais e representantes dos ministérios da Casa Civil, Integração Nacional, Cidades, Saúde e da Fazenda.

A discussão do projeto contou também com a presença de governadores, prefeitos e gestores de consórcios já operando, além das entidades representativas das prefeituras do 
País, como a Confederação Nacional dos Municípios. A presença desses entes foi importante para incorporar a realidade local ao projeto, prevendo e regulamentando as situações vividas pelos maiores interessados na regulamentação.

O projeto de lei de regulamentação foi encaminhado ao Congresso Nacional em 30 de junho de 2004 e aprovado em março de 2005, obtendo a sanção do presidente da República em 06 de abril, nascendo, enfim, a Lei no. 11.107/05.

Essa lei regulamentou todas as formas de associação entre entes públicos, permitindo a criação de entidades de direito público ou privado, desde que observados todos os procedimentos lá previstos. Previu a existência de consórcios públicos com personalidade jurídica, que poderiam ser criados sob o regime de direito público, constituindo-se em associações públicas, ou sob a forma de direito privado, como associações privadas.

Além de regulamentar e normatizar as situações anteriormente existentes, ela inovou o mundo jurídico ao criar uma nova instituição chamada consórcio público, diferente de outras já existentes, trazendo uma clara distinção dos convênios e/ou consórcios criados antes de sua vigência. Segundo Gasparini (2007, p. 346), o consórcio público da lei no 11.107/05:

\footnotetext{
"não se confunde com o consórcio clássico, pois destituído de personalidade jurídica. Tampouco confunde-se com os chamados consórcios que agrupavam seus membros através de entidades de natureza privada, pois a partir daí eram qualificados como pessoas jurídicas de natureza privada. Não eram mais consórcios." (GASPARINI, 2007, p. 346)
}

\section{Autonomia municipal na constituição federal}

Autonomia, segundo o conceito difundido pela doutrina pátria, traz ínsita a ideia de atuação limitada, na medida em que encerra uma margem de ação dentro dos limites traçados no ordenamento jurídico. Assim, não se confunde com soberania, própria do Estado Federal, de tal sorte que a autonomia municipal não é absoluta.

Mas o município, como pessoa jurídica, possui capacidade civil, podendo exercer direitos e contrair obrigações, não estando, para tanto, subordinado aos governos Estadual e Federal. Atua em igual grau de importância com os demais entes, por ser também 
considerado ente federativo pela Constituição Federal, que ainda lhe garante a tríplice capacidade de autogoverno, auto-administração e auto-organização.

O Consórcio Público, ainda que apenas na prática, ou seja, antes da regulamentação ordinária, já ratificava o princípio geral federativo, que pregava a união de forças entre as três espécies de entes federados para melhor administrar a res publica e alocar de forma mais personalizada os recursos disponíveis, de acordo com a necessidade e as características de cada região.

Assim, mais que a autonomia, o desejo dos administradores municipais é ter o apoio dos demais entes federados. Segundo Justen Filho (2008, p. 8):

\footnotetext{
"Qual é, então, do ponto de vista político, o espírito de Federalismo? É precisamente o espírito de associação. Ao se agrupar no seio de um Estado Federal, os Estados associados aceitam uma autoridade comum para o seu bem, para todos e para cada um, mas conservando um domínio próprio, que se manifesta pela sobrevivência de uma Constituição, de uma legislação, de uma administração e de uma justiça própria."
}

O federalismo cooperativo, que impera hoje deve respeitar os objetivos esposados no artigo 3ㅇ, da Constituição Federal, bem como o rol de competências materiais estabelecidos no seu artigo 23, mas de forma que a autonomia municipal, na nuance administrativa, permita ao mesmo aplicar de forma politicamente justa, os recursos fiscais obtidos em todas as esferas da Federação.

E a gestão associada de recursos vem sendo a única saída à política financeira centralizadora, que se instala até a presente data.

\section{Limitações constitucionais à de entes federados}

A lei no. 11.107/05 acentua que os "objetivos de interesse comum", dos consórcios públicos serão "determinados pelos entes de Federação que se consorciarem, observados os limites constitucionais". Tal dispositivo, naturalmente, faz remissão ao artigo 241 , da Constituição Federal, que atribui aos consórcios públicos a "gestão associada de serviços públicos". 
Depreende-se que a Constituição foi expressa ao limitar a utilização de consórcios públicos para a realização de serviços públicos. Dessa forma devem ser interpretados os “objetivos de interesse comum", previstos no art. 1ํ da lei dos consórcios públicos.

Para melhor entendimento do conceito legal de serviços públicos, salutar a lição de Bandeira de Mello (2007, p. 650):

\begin{abstract}
"Toda atividade de oferecimento de utilidade ou comodidade material destinada à satisfação da coletividade em geral, mas fruível singularmente pelos administrados, que o Estado assume como pertinente a seus deveres e presta por si mesmo ou por quem Ihe faça as vezes, sob um regime de Direito Público - portanto, consagrador de prerrogativas de supremacia e de restrições especiais -, instituído em favor dos interesses definidos como públicos no sistema normativo."
\end{abstract}

Para Cretella Júnior (1999, p. 402), serviço público é simplesmente "toda atividade que o Estado exerce para cumprir seus fins". Di Pietro (2002, p. 99) considera serviço público "toda atividade material que a lei atribui ao Estado para que a exerça diretamente ou por meio de seus delegados, com objetivo de satisfazer concretamente às necessidades coletivas, sob regime jurídico total ou parcialmente público".

Contemplando os princípios fundamentais, Freitas (2004, p. 85) os define como o "conjunto de atividades essenciais, assim consideradas pelo ordenamento jurídico, prestadas diretamente pelo Poder Público ou mediante delegação executória 'lato sensu', tendo em vista atender ao interesse geral e sob regência dos princípios constitucionais de Direito Administrativo".

A idéia recorrente em todos estes conceitos é o atendimento de necessidades coletivas, como núcleo do serviço público típico. Por esse prisma, os consórcios podem ser veiculados para a gestão associada de uma vasta gama de serviços públicos previstas na Constituição Federal como de competência estatal, como hospitais regionais ${ }^{3}$, convênios de ensino básico e treinamento profissional (Art. 30, inc. VI, da Constituição Federal), usinas de tratamento e reciclagem de resíduos urbanos, transportes coletivos (Art. 30, inc. $V$ da Constituição Federal), fornecimento de energia elétrica, como já ocorre em algumas regiões (Art. 149-A da Constituição Federal).

\footnotetext{
3 De se perceber a consonância com os preceitos constitucionais estabelecidos nos artigos 196 e 197 de nossa Carta Política, que instituem a prestação de serviços de saúde como "dever do Estado".
} 
Talvez a limitação constitucional mais importante seja a representada pelo $\S 2$, do artigo 1으, da Lei Federal №. 11.107/05, que buscou dar proteção ao pacto federativo, evitando que a União fizesse a aplicação de verbas em determinadas regiões, sem a participação do Estado, que é o responsável pelas políticas públicas no território que lhe é respectivo.

Segundo esse dispositivo, a União somente poderá se consorciar a municípios, quando os respectivos Estados também fizerem parte da gestão, confirmando a concepção proposta no projeto de lei.

O legislador parece ter negado mais adiante esse comando, ao possibilitar que a União celebre convênio diretamente com municípios, sem a participação dos Estados em que se encontram, a fim de viabilizar a descentralização e a prestação de políticas públicas em escalas adequadas (Art. 14 da Lei Federal no 11.107/05). Porém, é certo que essa

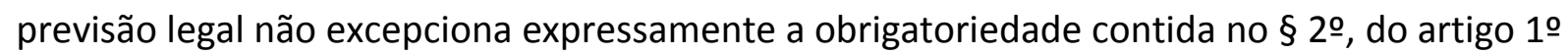
da Lei de Consórcios. Interpretar de outra forma seria considerar letra morta, o dispositivo em comento, o que não condiz com a boa hermenêutica.

\section{A gestão associada de serviços públicos}

A gestão associada de serviços públicos é expressão cunhada no artigo 241 , da Constituição Federal de 1988 e pressupõe a ação conjunta de dois ou mais entes federativos.

Não houve delimitação das hipóteses de gestão associada, mesmo por conta da lei federal. Mas apesar de enxuta, a lei no. 11.107/05 trouxe suficiente conceituação aos institutos que buscou tutelar.

Ao estabelecer os requisitos essenciais de uma gestão associada de serviços públicos, a legislação infraconstitucional terminou por regulamentar de forma global, a própria criação dos consórcios, de forma simples e eficaz: a lei no 11.107/05 pré-determina, apenas, as cláusulas essenciais do protocolo de intenções (Art. 4으, XI.), que deve preceder a elaboração do contrato de consórcio.

Já o contrato de programa teve tratamento mais detalhado. Por ele, pode-se constituir e regulamentar obrigações de um ente da federação para com outro, incluindo-se a Administração Indireta, possibilitando a gestão associada de serviços públicos sem que seja 
necessária a constituição de um consórcio público, sendo bastante a formalização de convênio de cooperação.

É importante salientar que o objetivo principal dos consórcios públicos é a conjugação de ações estatais perenes, pois a comunhão de esforços e de verbas dá certa grandiosidade ao investimento na obra ou serviço, o que não condiz com meras ações governamentais transitórias, de cunho eminentemente político.

\section{Natureza jurídica do consorcio público}

Quanto a natureza jurídica do consórcio, a lei no. 11.107/05 estabeleceu duas possibilidades: de direito público, voltada a gestão associada de serviços públicos através de associação pública, integrante da administração indireta de todos os entes consorciados; e de direito privado, através da reunião de entes federados em torno de uma pessoa jurídica de direito privado (Arts. 1으, § 1을 e 6으, inc. I e II, § 1으, da Lei oㅡ. 11.107/05).

Mesmo que constituída como uma pessoa jurídica de direito privado, a associação nestes moldes se submete às normas de direito público, quanto às seguintes situações: contratação de pessoas, obras e serviços e compra de bens, prestação de contas. A admissão de pessoal deve obedecer ao regime celetista (Art. 6ㅇ, § 2ㅇ da Lei no. 11.107/05). Trata-se de pessoa jurídica híbrida, pois criada como de direito privado e regida pelas normas de direito público, a exemplo dos partidos políticos.

O projeto de lei que deu origem à Lei dos Consórcios Públicos dava solução mais efetiva, pois considerava que todos os consórcios constituiriam pessoa jurídica de direito público (Art. 2ㅇinc. IV, do PL n. 3.884/04). Parece que o legislador quis dar uma opção aos consorciados, para conferir maior grau de liberdade à gerência do consórcio, evitando a estrutura burocrática das pessoas jurídicas de direito público.

Caso optem por unir-se na forma de pessoa jurídica de direito privado, os entes federados podem adotar a espécie de associação civil (art. 53 CC), como prevêem, expressamente, os artigos 15 e 4으, IV, da Lei no. 11.107/05, desde que a finalidade seja cultural ou assistencial, ficando excluídas dessa opção as sociedades, por vislumbrarem fins econômicos. ${ }^{4}$

\footnotetext{
4 “Art. 4ㅇ. São cláusulas necessárias do protocolo de intenções as que estabeleçam:...IV - a previsão de que o consórcio público é associação pública ou pessoa jurídica de direito privado sem fins econômicos;"
} 
De toda sorte, o hibridismo criado pela lei não se harmoniza com o sistema jurídico vigente, criando indissolúveis problemas hermenêuticos, chegando a inviabilizar a utilização prática dos institutos em algumas situações, como é o caso do art. 15, da lei no 11.107/05, que parece inviabilizar a constituição de consórcio formado por fundação (art 55, CC) : "no que não contrariar esta Lei, a organização e funcionamento dos consórcios públicos serão disciplinados pela legislação que rege as associações civis".

Há quem ateste a natureza contratual do consórcio público (Lei nำ11.107/05, art. 3ㅇ), o que faz concluir tratar-se de um negócio jurídico, um instrumento de acordo firmado entre os entes federados, a exemplo do consórcio de empresas do direito privado (Lei no 6.404/74, art. 278). Ao defender essa situação jurídica, concluem pela inexistência de personalidade jurídica, própria dos sujeitos de direito e obrigações. A responsabilidade, no caso, seria pessoal, dos chefes do Poder Executivo eleitos para os cargos de direção desse consórcio.

\section{Aplicação da Lei N. 11.107/05 aos consórcios intermunicipais anteriores a sua vigência}

As associações de municípios criadas sob as normas de direito privado não se convalidaram automaticamente em consórcios públicos, com o advento da Lei no 11.107/05, pois não observaram, na sua formação, as formalidades ditadas neste comando legal. Continuam, pois, sob o regime do direito privado.

\footnotetext{
"Tais entidades [associações de municípios] não formam consórcios, significando a reunião de Municípios em associações, de natureza privada, para fins de defesa de interesses dos Municípios filiados. Ausente está, nestas associações, o objetivo de realizar a gestão associada de serviços e praticar atividades de interesse comum." (MEDAUAR, 2006, p. 80)
}

Aliás, esse é o comando expresso do art. 19, da Lei no. 11.107/05: “o disposto nesta Lei não se aplica aos convênios de cooperação, contratos de programa para gestão associada de serviços públicos ou instrumentos congêneres, que tenham sido celebrados anteriormente a sua vigência." 
O Decreto №. 6.017/2007, que regulamentou esta lei dos consórcios públicos, chegou a contrariar esse comando, ao prever a possibilidade de convalidação dos consórcios anteriores a sua entrada em vigor:

“Art. 41. Os consórcios constituídos em desacordo com a Lei no 11.107, de 2005, poderão ser transformados em consórcios públicos de direito público ou de direito privado, desde que atendidos os requisitos de celebração de protocolo de intenções e de sua ratificação por lei de cada ente da Federação consorciado."

Assim, é possível a aplicação da Lei no. 11.107/05 aos consórcios criados anteriormente a sua vigência, desde que se faça a opção na forma do art. 41, do seu decreto regulamentador. Mas a ausência de adequação não prejudica a existência dos consórcios anteriores, que continuam sendo regulados pela legislação civil.

Contudo, da interpretação desta legislação, surge a dúvida: a partir da lei no 11.107/05 é possível a criação de associações de municípios sob o regime do direito privado, levando-se em conta que as associações regidas pelo direito civil eliminam a burocracia estatal e flexibiliza a administração do consórcio?

A Lei no. 11.107/05 fez incluir no art. 10, da Lei no. 8.429/92, o inciso XIV, que tipifica como improbidade administrativa "celebrar contrato ou outro instrumento que tenha por objeto a prestação de serviços públicos por meio da gestão associada sem observar as formalidades previstas na lei".

Portanto, está proibida por lei a gestão associada de serviços públicos, sem a obediência aos requisitos estabelecidos pela lei no 11.107/05, o que inviabiliza a criação de consórcios intermunicipais sob o regime de direito privado.

Esse dispositivo recebeu duras críticas de Di Pietro (2009), sob o argumento de que o ato de improbidade exige, para sua configuração, dolo e lesão efetiva ao erário, circunstâncias que não se apresentam na simples associação pelo regime privado.

\footnotetext{
“A lei não pode dizer que causa prejuízo ao erário - e, por isso, constitui improbidade administrativa - um ato que efetivamente não causa esse tipo de prejuízo. A hipótese destoa dos demais incisos da Lei de Improbidade Administrativa. Nem precisava haver qualquer alteração nessa lei, tendo em vista que a infringência a qualquer tipo de lei já constitui ato de improbidade previsto no art. 11 da Lei n. 8.429/92." (DI PIETRO, 2005, revista eletrônica)
} 
De qualquer forma, à partir da Lei no. 11.107/05 há comando legal específico, determinando a forma pública de associação de entes federados, quando o objeto seja a prestação de serviços públicos, o que faz nascer nova dúvida: e quando o objeto da associação não for a execução de serviços públicos, mas a consecução de simples objetivos de interesse comum, como é o caso da Associação Paulista de Municípios, ou a Confederação Nacional dos Municípios?

De imediato já se pode dizer que não haverá, no caso, improbidade administrativa, pois na tipificação constante do inciso XIV, do art. 10, da Lei no 8.429/92 não se encontra prevista a gestão associada de interesses comuns.

Note-se que a doutrina, ao conceituar os consórcios públicos, não diferencia "interesses públicos" de "interesses comuns". Para Gasparini (2007, p. 346) consórcio público é uma "pessoa jurídica sem finalidade econômica, pública ou privada, constituída unicamente por entes da federação para a realização de objetivos de interesses comuns".; para Meirelles (2005, p. 370), "são pessoas de direito públicos, quando associação pública, ou de direito privado, decorrentes de contratos firmados entre entes federados, após autorização legislativa de cada um, para a gestão associada de serviços públicos e de objetivos de interesse comum os consorciados, através de delegação e sem fins econômicos." e para Di Pietro (2009), são "associações formadas por pessoas jurídicas políticas (União, Estados, Distrito Federal e Municípios), com personalidade de direito público ou de direito privado, criadas mediante autorização legislativa, para a gestão associada de serviços públicos.".

O regulamento da Lei de Consórcios Públicos também fala de "interesse comum" ao conceituar o consórcio público, parecendo referir-se implicitamente a "interesse público":

\footnotetext{
“Consórcio público: pessoa jurídica formada exclusivamente por entes da Federação, na forma da Lei no 11.107, de 2005, para estabelecer relações de cooperação federativa, inclusive a realização de objetivos de interesse comum, constituída como associação pública, com personalidade jurídica de direito público e natureza autárquica, ou como pessoa jurídica de direito privado sem fins econômicos;" ( Decreto no. 6.017/2007, art. 2ํ, I)
}

Apenas em seu artigo 3ํ, I, menciona a "gestão associada de serviços públicos" como um dos objetivos do consórcio público. É de se observar, também, que vários objetivos ali elencados são comuns a outras formas de cooperação: 
“I - a gestão associada de serviços públicos;

II - a prestação de serviços, inclusive de assistência técnica, a execução de obras e o fornecimento de bens à administração direta ou indireta dos entes consorciados; III - o compartilhamento ou o uso em comum de instrumentos e equipamentos, inclusive de gestão, de manutenção, de informática, de pessoal técnico e de procedimentos de licitação e de admissão de pessoal;

IV - a produção de informações ou de estudos técnicos;

$\mathrm{V}$ - a instituição e o funcionamento de escolas de governo ou de estabelecimentos congêneres;

VI - a promoção do uso racional dos recursos naturais e a proteção do meioambiente;

VII - o exercício de funções no sistema de gerenciamento de recursos hídricos que Ihe tenham sido delegadas ou autorizadas;

VIII - o apoio e o fomento do intercâmbio de experiências e de informações entre os entes consorciados;

$X$ - a gestão e a proteção de patrimônio urbanístico, paisagístico ou turístico comum;

X - o planejamento, a gestão e a administração dos serviços e recursos da previdência social dos servidores de qualquer dos entes da Federação que integram o consórcio, vedado que os recursos arrecadados em um ente federativo sejam utilizados no pagamento de benefícios de segurados de outro ente, de forma a atender o disposto no art. 1o, inciso V, da Lei no 9.717, de 1998;

$\mathrm{XI}$ - o fornecimento de assistência técnica, extensão, treinamento, pesquisa e desenvolvimento urbano, rural e agrário;

XII - as ações e políticas de desenvolvimento urbano, sócio-econômico local e regional; e

XIII - o exercício de competências pertencentes aos entes da Federação nos termos de autorização ou delegação."

É de se concluir, assim, pela observância obrigatória da forma de associação prevista na lei no. 11.107/05, quando o objeto da gestão for a execução de serviços públicos, na definição dada pelo art. 2ํ, XVI, do Decreto no. 6.017/2007: “atividade ou comodidade material fruível diretamente pelo usuário, que possa ser remunerado por meio de taxa ou preço público, inclusive tarifa".

Por fim, em se tratando de interesses comuns distintos do conceito de serviços públicos, sua gestão associada, ainda que por entes da federação, dispensa a constituição de consórcio público, sem que o gestor incorra em ato de improbidade administrativa. Mas por conta da atuação do Tribunal de Contas, justificada no art. 71, II, da Constituição Federal, mesmo sem se sujeitarem às normas da Lei no. 11.107/05, as associações de municípios criadas antes do seu advento têm sido obrigadas a observar o regime público para a contratação de obras, serviços e empregados: 
“c) As exigências constitucionais impositivas de impessoalidade, relativas à licitação, contratos, prestação de contas e concurso público para admissão de pessoal se aplicam a todos os consórcios, anteriores ou posteriores ao advento da Lei $11.107 / 05 ;^{\prime \prime}$

“(...) por receber dinheiro público, não têm as associações microrregionais de municípios, como fugir da incidência dos princípios constitucionais estatuídos no art. 37 da Constituição da República, devendo contratar pessoal por meio de concurso público e reger-se, nas hipóteses de contratações com terceiros, pela lei que regulamenta a licitação e os contratos administrativos, princípios assecuratórios da moralidade administrativa." ( TCE/MG, consulta no. 731.118.)

A lei no. 8.666/93 contém comando especial obrigando essas associações, ou qualquer entidade controlada por um ente da federação, a observar as normas gerais de licitações e contratos.

Note-se que, por previsão expressa da Lei №. 11.107/05, a licitação para a contratação de consórcio público por administração direta ou indireta consorciada, é dispensada, mesmo porque não faria sentido, uma vez formado consórcio, iniciar procedimento licitatório para delegar a atividade de prestação do serviço objeto dessa gestão associada.

A licitação também foi dispensada na hipótese de contratação de entidade da Administração, no âmbito da gestão associada, para a prestação de serviços públicos (Lei no. . 8.666/93, art. 24, alterado pelo art. 17, da Lei no. 11.107/05). Para esse fim, a lei não fez diferença entre o consórcio constituído na forma de pessoa jurídica de direito privado (associação civil) e o constituído sob a pessoa jurídica de direito público (associação pública).

Essa dispensa, por um lado, agiliza a contratação pelos entes consorciados, mas incorre em afronta ao princípio da seleção da proposta mais vantajosa para a administração (MILESKI, 2004, p. 222), o que favorece a criação de consórcios com o intuito de burlar o sistema licitatório.

Por isso a fiscalização do Tribunal de Contas é imprescindível, para evitar que a banalização da corrupção venha por em descrédito esse recente instituto, o que também pode ser reforçado pela previsão, no protocolo de intenções, de mecanismos de controle social ${ }^{6}$, de audiências públicas periódicas e ouvidorias, aumentando, assim, a participação

\footnotetext{
${ }^{5}$ TCE/RS, Processo no 10004-0200/07-4

6 Neste aspecto, Maria Sylvia Zanella Di Pietro no artigo "Inovações no Direito Administrativo Brasileiro" (Revista Interesse Público n. 30, março/abril de 2005, p. 47-48), refere que é inerente ao Estado Democrático a "idéia de participação do cidadão na gestão e no controle da Administração Pública...".
} 
popular na fiscalização e avaliação do desempenho do consórcio. Prima-se, dessa forma, pelo respeito aos princípios insculpidos no art. 37, da Constituição Federal, notadamente pela transparência e pela eficiência.

\section{Vantagens e desvantages do regime instituído pela Lei no. 11.107/05}

Em termos práticos, não se vislumbra vantagem na criação de consórcios sob a égide do direito privado, mesmo que na intenção de dar maior flexibilidade à gestão, já que todas as atividades relevantes (aquisição de produtos e serviços, obras de engenharia, admissão de pessoal e prestação de contas) serão disciplinadas por normas de direito público.

No caso de um consórcio intermunicipal constituído pelo regime privado de direito, antes do advento da lei no. 11.107/05, sua convalidação aos termos desta o levará a integrar a Administração Indireta dos consorciados e a executar atribuições e competências de uma autarquia municipal, o que implica em algumas vantagens:

a) ampliação dos prazos processuais para contestar e recorrer, além da proibição de constrição de seus passivos antes do trânsito em julgado da sentença e pagamento através de precatórios;

b) adequação e execução orçamentária vinculada a Administração Direta, mediante transferências financeiras em regime intragovernamental;

c) transferências financeiras estatais "fundo a fundo"; e

d) autonomia administrativa e financeira.

Por outro lado, a autarquia não tem sido vista com bons olhos pelos gestores públicos e consultores administrativistas, pois sua gestão não poderá ser exercida por um chefe do Poder Executivo, como comumente é feito em consórcios públicos, tendo em vista a impossibilidade de um prefeito dirigir órgão da Administração Indireta integrante da sua própria Administração.

Além disso, as autarquias dependem de aprovação do orçamento da Administração Direta respectiva, tendo em vista a dependência financeira, o que gera disputa entre órgãos e secretarias, por uma mesma fonte de recursos (orçamento municipal).

Com o advento do terceiro setor, floresceram aas Organizações Não Governamentais, dentre elas a Organização da Sociedade Civil de Interesse Público - OSCIP 
( Lei no. 9.790/99.) e as entidades filantrópicas e assistenciais que atuam de forma suplementar no Sistema Único de Saúde (Art. 25, da lei no 8.080/90), ou seja, agem onde o Estado é deficitário no atendimento das necessidades da população.

Os consórcios e as parcerias constituídos nesses moldes são mais desburocratizados e dão maior autonomia financeira e administrativa ao gestor, que gerencia segundo a regras de mercado, permitindo, ainda, a subvenção de verbas por parte da Administração Direta de forma mais livre.

\section{A responsabilidade dos consorciados e dos prefeitos por atos do consorcio intermunicipal}

A lei no. 11.107/05 previu expressamente o controle externo dos consórcios públicos e privados, ao consignar que "a execução das receitas e das despesas do consórcio deverá obedecer às normas de direito financeiro aplicáveis às entidades públicas" (Art. 9 da Lei Federal no. 11.107/05).

O projeto de lei atribuía a responsabilidade ao representante legal, pela contas do consórcio, mas não delimitava a competência territorial do Tribunal de Contas, no caso de gestão associada composta por entes federativos de natureza diversa.

A omissão foi sanada mediante a previsão de que "o consórcio público está sujeito à fiscalização contábil, operacional e patrimonial pelo Tribunal de Contas competente para apreciar as contas do Chefe do Poder Executivo representante legal do consórcio" (Art. 9o, Parágrafo único, da Lei Federal no. 11.107/05), o que atende ao princípio da economicidade, pois evita que um mesmo consórcio seja fiscalizado por Tribunais de competências diferentes. No caso dos contratos de rateio, a fiscalização será realizada pelo Tribunal responsável pela análise das contas de cada participante.

Quanto aos agentes públicos, a lei no. 11.107/05 excluiu sua responsabilidade pessoal, civil e administrativa, pelos atos de gestão do consórcio, notadamente pelas obrigações assumidas pelo consórcio, desde que em conformidade com a lei ou o seu estatuto.

Essa prerrogativa é uma proteção contra ingerências surgidas entre os diversos agentes políticos participantes da gestão possam resultar em manobras administrativas ou judiciais como estratagema para fazer prevalecer seu interesse naquele empreendimento. 
Também dá liberdade ao gestor para conduzir as negociações sem temor ou pressão pelo comprometimento do seu patrimônio particular.

\section{Conclusão}

É fácil concluir que a lei no. 11.107/05, copiando o conceito aberto do artigo 241, da Constituição Federal - gestão associada de serviços públicos conseguiu estimular a utilização do consórcio público como modalidade de gestão mais eficiente e adequada para atingir a proposta de descentralização do Constituinte de um federalismo cooperativo.

Porém, a despeito regulamentar no mundo jurídico uma situação fática já existente há tempos, a lei consorcial trouxe ao revés alguns entraves, como a forma privada de consórcio (associação civil), o que criou dupla sujeição de regime jurídico (público e privado), sem razão plausível, de ordem prática, a justificar a excepcionalidade.

O legislador perdeu a oportunidade de terminar com o hibridismo que prevalecia até a vigência da lei, onde associações criadas sob a égide do direito privado foram levadas à fiscalização pelas Cortes de Contas, mesmo sem a devida previsão legal.

Faltou também uma conceituação legal da associação pública, a mais nova forma de pessoa jurídica de direito público interno brasileira, encargo que ficou relegado à doutrina e à jurisprudência, deixando, assim, margem para muita divergência.

Retificados os erros e omissões da lei, seja pela exegese ou pela própria via legislativa, é de se comemorar a vigência da lei, por trazer segurança jurídica e controle na implementação da gestão associada de serviços públicos, o que favorecerá a sua proliferação, de modo a fortalecer a autonomia das microrregiões, que poderão, dessa forma, contornar a deficitária política de descentralização política até então utilizada pelos entes federados fictícios.

E os consórcios existentes poderão ser adequar aos termos da lei no. 11.107/05 para gozar dos benefícios do regime público de direito e, dessa forma, gerir os recursos comuns com mais facilidade e transparência, já que as associações privadas, na sua atuação deverão observar de qualquer forma as normas de direito público.

A Associação Pública criada pela lei consorcial é fenômeno novo, a demandar mais estudos por parte da doutrina, bem como um enfrentamento dos aspectos concretos de sua 
aplicação, perante a jurisprudência brasileira, com o intuito único de melhorar ou até mesmo suprir a falta de conceitos e definições da lei.

Assim, espera-se que a Lei no. 11.107/05 consiga cumprir o objetivo de finalmente engendrar o princípio federativo cooperativo entre os entes da Federação, de forma a trazer a tão sonhada justiça social a todas as regiões do país.

\section{Referências}

BRASIL. Constituição (1988). Constituição da República Federativa do Brasil. Brasília, DF: Senado, 1988.

CARVALHO FILHO, José dos Santos. Manual de Direito Administrativo. 17. ed. Rio de Janeiro: Lúmen Júris, 2007.

BREMAEKER, François E. J. de. Os consórcios na administração municipal. Rio de Janeiro: IBAM/APCM/NAPI/IBAMCO, 2001.

VIOLIN, Tarso Cabral. Terceiro Setor e as parcerias com a Administração Pública. Belo Horizonte: Fórum, 2006.

JÚNIOR, José Cretella. O controle dos atos administrativos. 3.ed. rev. e ampl.. São Paulo: Malheiros, 2004.

MEDAUAR, Odete. Direito administrativo moderno. 4.ed. rev., atual. e ampl. São Paulo: Editora Revista dos Tribunais, 2000.

MEIRELLES, Hely Lopes. Direito municipal brasileiro. 13.ed. atual. São Paulo: malheiros, 2003.

GASPARINI, Diógenes. Direito Administrativo. 12. ed. São Paulo: Saraiva, 2007.

MELLO, Celso Antônio Bandeira de. Curso de direito administrativo. 15.ed. ref. ampl. e atual.. São Paulo: Malheiros, 2003.

PIETRO, Maria Sylvia Zanella Di. Inovações no direito administrativo brasileiro. Interesse Público. Ano 6. no 30, março/abril de 2005. Porto Alegre: Notadez, 2005.

. Direito Administrativo. 14. ed. São Paulo: Atlas, 2002. 99. Contratos de gestão. contratualização do controle administrativo sobre a administração indireta e sobre as organizações sociais. Revista da Procuradoria Geral do Estado de São Paulo. Disponível em: < http://www.pge.sp.gov.br/centrodeestudos/revistaspge/revista2/artigo9.htm

VENOSA, Sílvio de Salvo. Direito Civil. 6. ed. São Paulo: Atlas, 2006. 
SILVA, Cleber Demetrio Oliveira da. A regulamentação dos consórcios públicos à luz do projeto de lei no. 3.884/2004. Jus Navigandi, Teresina, a. 9, n. 654, 22 abr. 2005. Disponível em: <http://www1.jus.com.br/doutrina/texto.asp?id=6614>.

FREITAS, Juarez. O controle dos atos administrativos. 3.ed. rev. e ampl.. São Paulo: Malheiros, 2004. p. 87.

DI PIETRO, Maria Sylvia Zanella. O consórcio público na lei n. 11.107, de 6.04.2005. In: Revista Eletrônica de Direito do Estado, Salvador, n. 03, jul-ago-set, 2005. Disponível em http://www.direitodoestado.com. Acesso em 27 de maio de 2009.

CARVALHO FILHO, José dos Santos. Manual de Direito Administrativo. 17. ed. Rio de Janeiro: Lúmen Júris, 2007, p. 199.

PIETRO, Maria Sylvia Zanella Di. Inovações no direito administrativo brasileiro. Interesse Público. Ano 6. no. 30, março/abril de 2005. Porto Alegre: Notadez, 2005, p. 55.

JÚNIOR, José Cretella. Curso de direito administrativo. 16. ed. rev. e atual. Rio de Janeiro: Revista Forense, 1999, p. 402.

PIETRO, Maria Sylvia Zanella Di. Direito Administrativo. 14. ed. São Paulo: Atlas, 2002, p. 99.

FREITAS, Juarez. O controle dos atos administrativos. 3. ed. rev., e ampl.. São Paulo: Malheiros, 2004. p. 85.

MILESKI, Helio Saul. O controle das licitações e o papel dos tribunais de contas, judiciário e ministério público. Interesse Público. Ano 5. no. 27, março/abril de 2004. Porto Alegre:

Notadez, 2004, p. 222. 